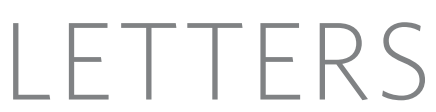

\title{
Endonuclease-independent LINE-1 retrotransposition at mammalian telomeres
}

\author{
Tammy A. Morrish ${ }^{1 \star}+$, José Luis Garcia-Perez ${ }^{1 \star}$, Thomas D. Stamato ${ }^{3}$, Guillermo E. Taccioli ${ }^{4}$, JoAnn Sekiguchi ${ }^{1,2}$ \\ \& John V. Moran ${ }^{1,2}$
}

Long interspersed element-1 (LINE-1 or L1) elements are abundant, non-long-terminal-repeat (non-LTR) retrotransposons that comprise $\sim 17 \%$ of human $\mathrm{DNA}^{1}$. The average human genome contains $\sim 80-100$ retrotransposition-competent L1s (ref. 2), and they mobilize by a process that uses both the $\mathrm{L} 1$ endonuclease and reverse transcriptase, termed target-site primed reverse transcription $^{3-5}$. We have previously reported an efficient, endonucleaseindependent $\mathrm{L} 1$ retrotransposition pathway $\left(\mathrm{EN}_{\mathrm{i}}\right)$ in certain Chinese hamster ovary ( $\mathrm{CHO}$ ) cell lines that are defective in the non-homologous end-joining (NHEJ) pathway of DNA doublestrand-break repair ${ }^{6}$. Here we have characterized $\mathrm{EN}_{\mathrm{i}}$ retrotransposition events generated in $\mathrm{V} 3 \mathrm{CHO}$ cells, which are deficient in DNA-dependent protein kinase catalytic subunit (DNA-PKcs) activity and have both dysfunctional telomeres and an NHEJ defect. Notably, $\sim 30 \%$ of $\mathrm{EN}_{\mathrm{i}}$ retrotransposition events insert in an orientation-specific manner adjacent to a perfect telomere repeat $\left(5^{\prime}-\right.$ TTAGGG-3'). Similar insertions were not detected among $\mathrm{EN}_{\mathrm{i}}$ retrotransposition events generated in controls or in XR-1 CHO cells deficient for XRCC4, an NHEJ factor that is required for DNA ligation but has no known function in telomere maintenance. Furthermore, transient expression of a dominantnegative allele of human TRF2 (also called TERF2) in XRCC4deficient XR-1 cells, which disrupts telomere capping, enables telomere-associated $\mathrm{EN}_{\mathrm{i}}$ retrotransposition events. These data indicate that L1s containing a disabled endonuclease can use dysfunctional telomeres as an integration substrate. The findings highlight similarities between the mechanism of $\mathrm{EN}_{\mathrm{i}}$ retrotransposition and the action of telomerase, because both processes can use a $3^{\prime} \mathrm{OH}$ for priming reverse transcription at either internal DNA lesions or chromosome end $s^{7,8}$. Thus, we propose that $\mathrm{EN}_{\mathrm{i}}$ retrotransposition is an ancestral mechanism of RNAmediated DNA repair associated with non-LTR retrotransposons that may have been used before the acquisition of an endonuclease domain.

We previously reported an endonuclease-independent pathway of L1 retrotransposition in a DNA-PKcs-deficient (V3) cell line (Fig. 1a; see also Supplementary Table 1$)^{6}$. In addition to its role in NHEJ, the DNA-PKcs protein probably contributes to telomere capping, as embryonic fibroblasts derived from two $\mathrm{DNA}-\mathrm{PKcs}{ }^{-1-}$ mouse strains exhibit an increase in anaphase bridges and telomere fusions ${ }^{9,10}$. Consistent with published results ${ }^{10-12}$, V3 cells exhibit an increase in the number of anaphase bridges when compared to the AA8 parental cell line (Supplementary Fig. 1a). Moreover, 53BP1, a protein that is recruited to DNA double-strand breaks and dysfunctional telomeres, can localize to chromosomal ends in V3 cells ${ }^{13-15}$ (Supplementary Fig. 1b, c).
To gain an insight into the mechanism of L1 retrotransposition in V3 cells, we characterized the sites of genomic integration. Four retrotransposition events generated from an endonuclease-proficient L1 showed the attributes of target-site primed reverse transcription (TPRT) because they are $5^{\prime}$-truncated, end in a poly $(\mathrm{A})$ tail, integrate into an L1 endonuclease consensus cleavage site, and most were flanked by variable-length target-site duplications (Fig. 1b; insertions $1-4)^{16,17}$. The remaining insertion (Fig. 1b; insertion 5) is both $5^{\prime}$ - and $3^{\prime}$-truncated and lacks a discernible target-site duplication. The $5^{\prime}$ flank contains a 203-base-pair (bp) sequence that is homologous to a hamster sub-telomere-like repeat (AF306800; $P=1 \times 10^{-41}$ ) that is also present at some pericentromeric and interstitial regions of $\mathrm{CHO}$ chromosomes $^{18}$. Thus, most endonuclease-proficient L1 retrotransposition events in V3 cells occur by $\mathrm{TPRT}^{6}$, although one insertion is associated with a telomere-like sequence at its $5^{\prime}$ end and is similar structurally to previously described $\mathrm{EN}_{\mathrm{i}}$ retrotransposition events ${ }^{6}$.

We next examined $\mathrm{EN}_{\mathrm{i}}$ retrotransposition events in $\mathrm{V} 3$ cells. Two insertions (Fig. 1b; insertions 8 and 9) were structurally similar to previously characterized $\mathrm{EN}_{\mathrm{i}}$ events (Fig. 1b; insertions 6 and 7$)^{6}$. The last 532 bp flanking the $3^{\prime}$ end of insertion 9 showed homology to the same hamster subtelomere-like repeat $\left(\operatorname{AF} 306800\left(P=7 \times 10^{-68}\right)\right)$ flanking the $5^{\prime}$ end of insertion 5. In comparison, the sequences flanking the $3^{\prime}$ end of insertions 10 and 11 had different poly(A) tail lengths ( $\sim 33$ bases and $\sim 120$ bases, respectively) that are followed directly by the complement of a perfect series of telomere repeats ( 24 and 10 copies, respectively). The integrity of the repeats then degenerates and is followed by host DNA sequences. These data suggest that both $\mathrm{EN}_{\mathrm{i}}$ retrotransposition events initiated at related but distinct telomere repeats in $\mathrm{V} 3$ cells.

We next developed a polymerase chain reaction (PCR)/Southern blot assay to determine the frequency of telomere-associated $\mathrm{EN}_{\mathrm{i}}$ retrotransposition events (Fig. 2a). As controls, we amplified the L1-telomere junction fragments from genomic DNA of insertions 10 and 11 using a primer specific to the $3^{\prime}$ end of our engineered L1 (that is, L1end326) and one of three primers specific for either the telomere-L1 junction (that is, telo10T and telo3T) or telomere sequence alone (that is, telo; see Methods). Southern blot analysis using an L1 probe (that is, L1end191) identified a 326-bp product from insertion 10 genomic DNA using each primer set (Fig. 2b; lane 33-poly(A)). A heterogeneously sized product often was amplified from insertion 11 (Fig. 2b; lane 120-poly(A)), which probably reflects difficulty amplifying through the $\sim 120$-bp poly(A) tail. Sequencing confirmed the identity of the products (not shown).

The PCR assay was then used to screen genomic DNAs isolated from $17 \mathrm{EN}_{\mathrm{i}}$ insertions generated in V3 cells. Experiments conducted with L1end326 and telo10T revealed products in cell lines $3 \mathrm{~L}, 10 \mathrm{E}$,

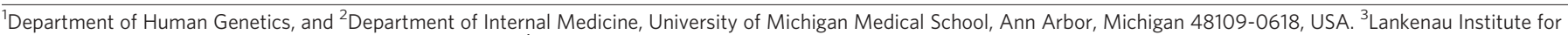

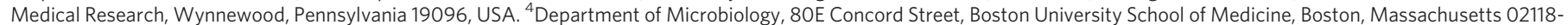

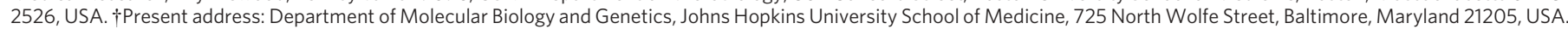
*These authors contributed equally to this work. 
10L, 13E, 14E and 14L (Fig. 2b). In cell lines 10 and 14, the product was evident in both early (E) and a later (L) passage cell lines (see Methods). In cell line 3, we only detected a product in the later passage cell line, indicating that the insertion occurred during its establishment. In cell line 13, we only observed a product in the early passage cell line, suggesting a failed PCR reaction from the later passage cell line. We also observed faint bands of various sizes in other lanes (Fig. 2b, lanes 2E, 4L, 9E); however, sequencing revealed that only the intense bands in cell lines 3, 10, 13 and 14 contained bona fide L1-telomere junction fragments (see Fig. 2c).

To rule out nonspecific amplification owing to the ten deoxythymidine residues in the telo10T primer, PCR assays were conducted with the L1end326-telo3T or L1end326-telo primer pairs (Fig. 2b and data not shown). Again, cell lines 3, 10, 13 and 14 yielded positive signals, corroborating the above results. Sequencing revealed that the products have poly (A) tails that range from approximately 13-86 bases (Fig. 2c). However, we also detected a signal in cell line 5 (Fig. 2b, right panel). Sequencing demonstrated that the $\mathrm{EN}_{\mathrm{i}} \mathrm{L} 1$ insertion present in cell line 5 is truncated at the SV40 poly(A) cleavage site and only contains two deoxyadenosine residues at the L1telomere junction (Fig. 2c), explaining why this product was not amplified using the L1end326-telo10T primer pair. Further analysis of the L1end326-telo PCR products revealed that the L1 poly $(\mathrm{A})$ tail is always flanked by the complement of a perfect ( $5^{\prime}$-CCCTAA-3') telomere repeat (Fig. 2c), and we confirmed these results using different telomere primers (Supplementary Fig. 2). Finally, primer pairs designed to detect telomere insertions in the opposite polarity did not yield PCR products (Supplementary Table 3a). These data indicate that the $3^{\prime} \mathrm{OH}$ of a terminal telomere repeat (5' -TTAGGG$3^{\prime}$ ) was used to initiate reverse transcription.

To confirm $\mathrm{EN}_{\mathrm{i}}$ retrotransposition at a chromosomal end, we performed fluorescence in situ hybridization (FISH) on V3 cells using a $4.5-\mathrm{kb}$ probe containing host genomic DNA sequences flanking the telomere repeats present in insertion 10 (Figs $1 \mathrm{~b}$ and $2 \mathrm{~d}$ ). If our engineered L1 inserted at a telomere end, this probe should hybridize to subtelomeric sequences. Approximately $83 \%$ of the positive FISH signals in cells at metaphase localized to the subtelomeric regions on five different chromosomes (Fig. 2d; see also Supplementary Table 2, categories A-D). The remaining cells at metaphase showed FISH signals located at different interstitial chromosomal locations (Supplementary Table 2, category E). We also observed di-centric chromosomes and karyotypic variation among individual V3 cells (Supplementary Table 2, category D), supporting the hypothesis that loss of the DNA-PKcs protein results in telomere dysfunction and genome instability ${ }^{9,10,12}$.

We next examined whether an endonuclease-proficient L1 could retrotranspose at telomeres in parental AA8 cells and V3 cells (Supplementary Fig. 3e, f, and data not shown). As above, some faint bands were visible after Southern blotting; however, sequencing indicated that they were nonspecific products (data not shown).

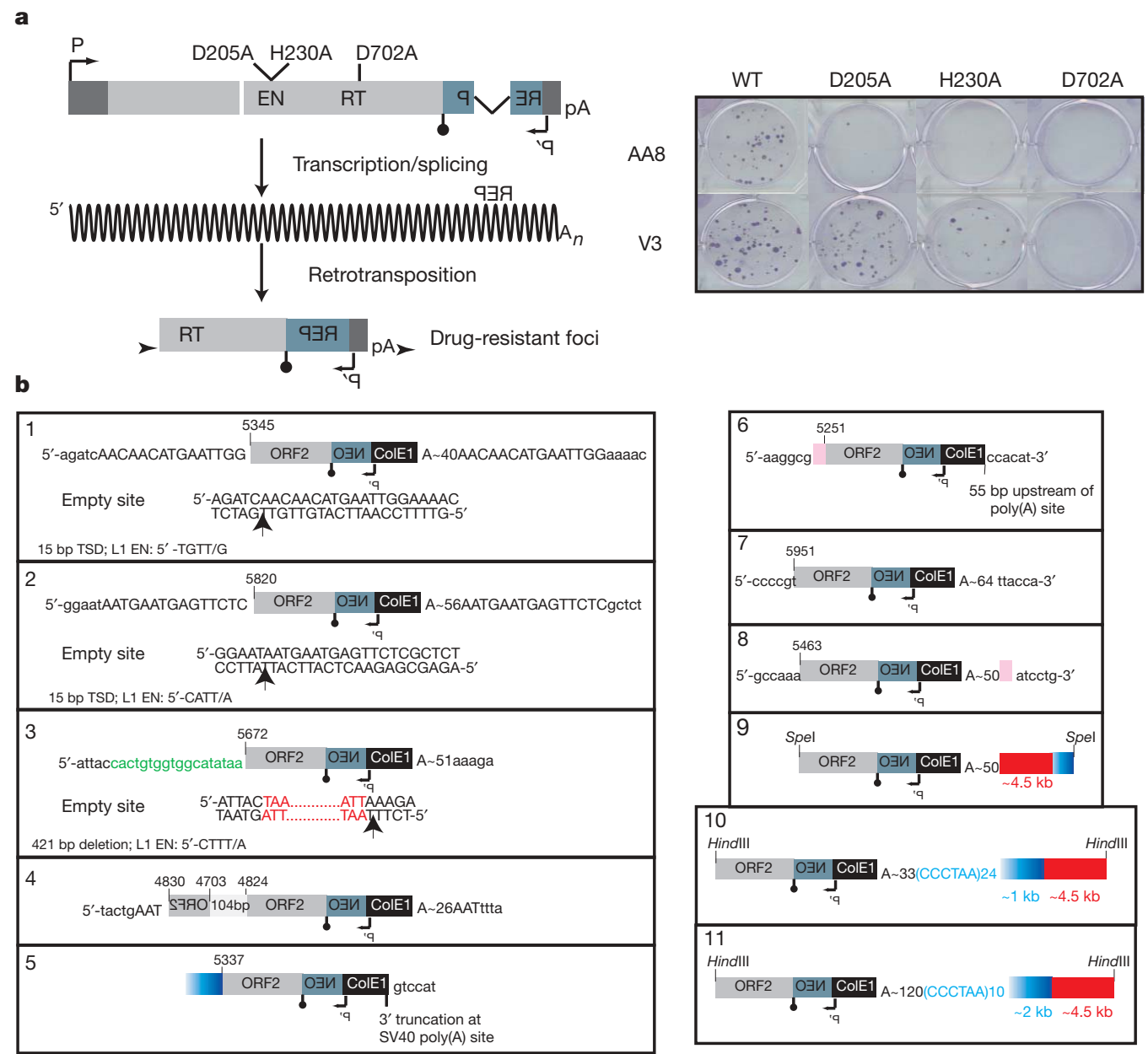

Figure 1 Characterization of $\mathbf{L 1}$ retrotransposition insertions in V3 cells. a, A wild-type (WT) L1 with a retrotransposition indicator cassette (Rep). The EN (D205A and H230A) and RT (D702A) mutants are shown. Right: blasticidin-resistant foci in AA8 and V3 cells. b, Diagrams of wild-type (left) and $\mathrm{EN}_{\mathrm{i}}$ (right) retrotransposition events. The pre-integration (insertions 1-3) and post-integration sites are shown. Arrowheads, L1 EN cleavage site; uppercase lettering, target site duplications (TSD); green lettering, non-L1 'filler' $\mathrm{DNA}^{6}$; blue lettering/rectangles, putative telomere/subtelomeric sequence; red and pink rectangles, genomic and cDNA sequences, respectively. L1 numbering is relative to L1.2 (GenBank accession

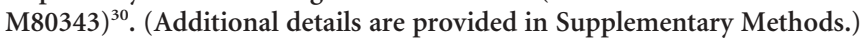


Moreover, the faint products were not observed using primers that could amplify a larger L1-telomeric junction fragment (Supplementary Table 3). Thus, most wild-type L1 retrotransposition insertions in both AA8 and V3 cells seem to initiate by conventional TPRT ${ }^{6}$, although it is possible that the sample size of our experiment is too small $(n=49)$ to detect telomere-associated events. Similar experiments failed to detect L1-telomere junction fragments among cohorts of $\mathrm{EN}_{\mathrm{i}}$ retrotransposition events in either AA8 or XRCC4deficient cells (Supplementary Figs 3 f and 4), suggesting that telomereassociated retrotransposition is due to the dysfunctional telomere phenotype associated with V3 cells.

We then assayed $\mathrm{EN}_{\mathrm{i}}$ retrotransposition in two clonal V3 cell lines that expressed a mouse DNA-PKcs complementary DNA (mDNAPKcs comp5 and mDNA-PKcs comp15; Supplementary Fig. 3a). V3 cells exhibit increased radiation sensitivity and defects in a lymphoidspecific DNA rearrangement, $\mathrm{V}(\mathrm{D}) \mathrm{J}$ recombination, when compared with parental AA8 cells; the murine DNA-PKcs protein complements these phenotypes (Supplementary Fig. 3b, c). However, EN $_{i}$ retrotransposition occurred at similar efficiencies in the $\mathrm{V} 3$ and DNA-PKcs complemented cell lines (Supplementary Table 1 and Supplementary Fig. 3d), and the complemented cells did not exhibit a significant decrease in anaphase bridges when compared to V3 cells (Supplementary Fig. 1a). Similar results were also obtained from V3 cell lines that were complemented with a human DNA-PKcs gene ${ }^{19-23}$ (data not shown). Characterization of $\mathrm{EN}_{\mathrm{i}}$ retrotransposition events

a

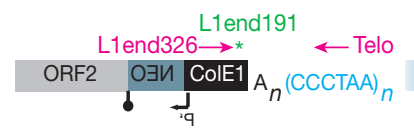

b

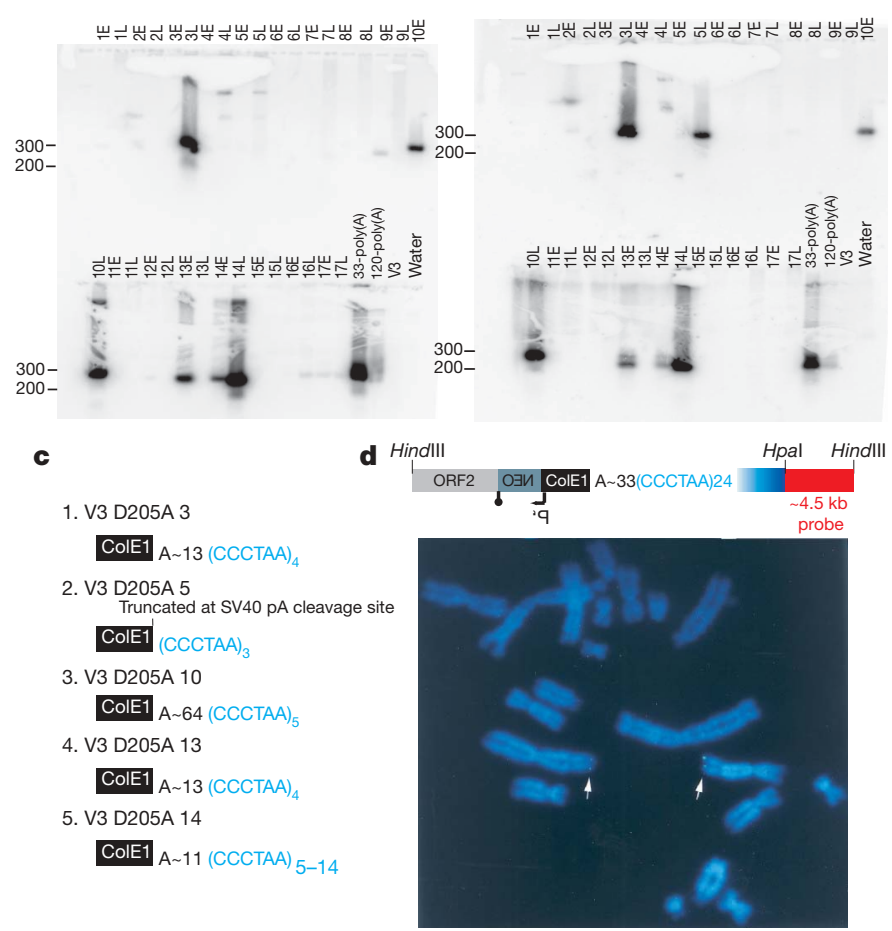

Figure 2 | $\mathrm{EN}_{\mathrm{i}}$ retrotransposition initiates at the telomere. a, Primers used in the PCR (pink)/Southern blot (green) assay are shown above the diagram. b, Each lane contains PCR products from 17 DNAs from early (E) or later (L) passage clonal G418-resistant cell lines hybridized with L1end191.

33-poly(A) and 120-poly(A) are positive control DNAs from insertions 10 and 11 (Fig. 1b). Size markers (bp) and primer pairs are shown. c, Sequences of the PCR products using the Llend326-teloTTA primer pair. d, FISH results in V3 cells using the $\sim 4.5$-kb probe from insertion 10 (red rectangle). (Results are summarized in Supplementary Table 2.) White arrows indicate positive FISH signals. a
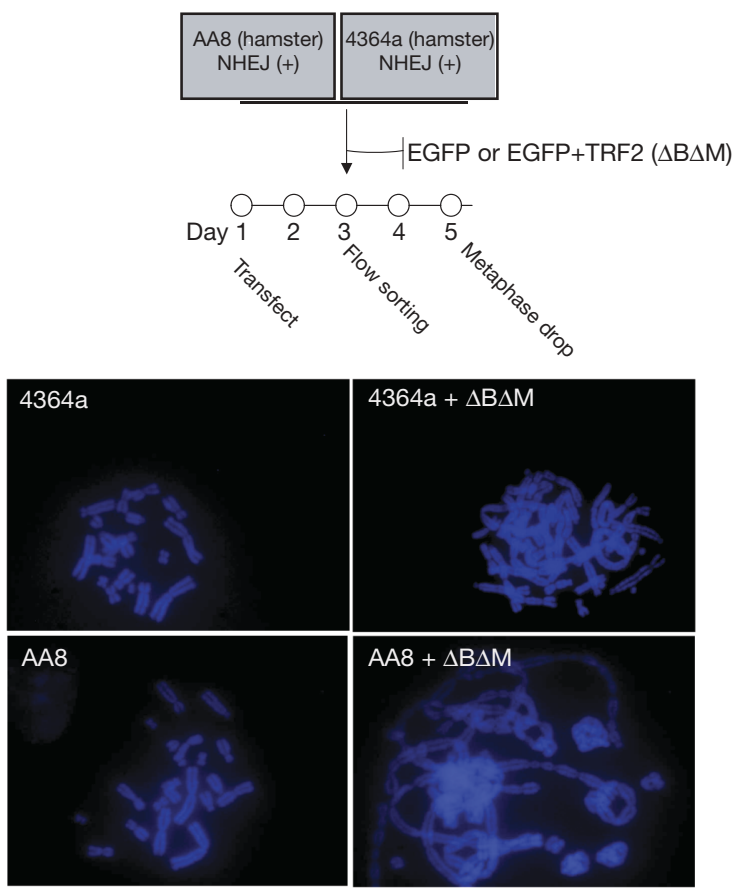

b

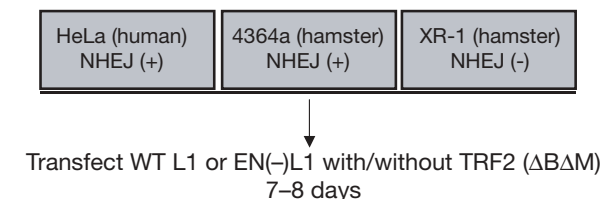

$$
\text { 7-8 days }
$$

Pool genomic DNAs

PCR/Southern blot analysis

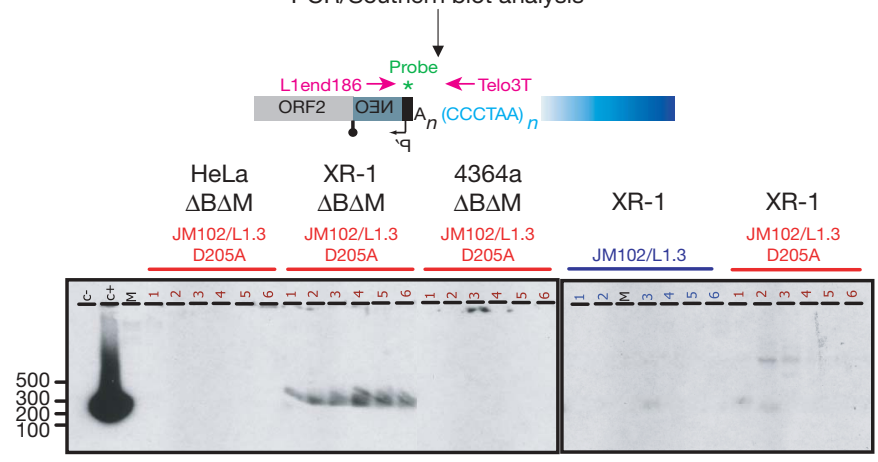

c

${ }_{\triangle B \Delta M}$ JM102/L1.3 D205A pool $4 \quad \Delta B \Delta M$ JM102/L1.3 D205A pool 5

$\triangle \mathrm{B} \Delta \mathrm{M}$ JM102/L1.3 D205A pool 6
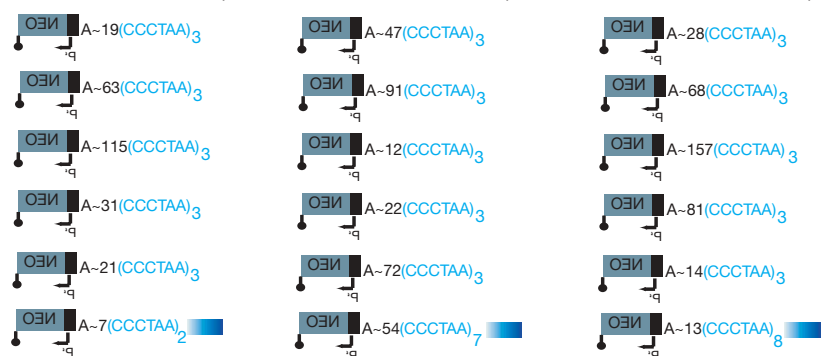

Figure 3 | Destabilization of telomeres in XRCC4-deficient cells allows for telomere-associated $\mathrm{EN}_{\mathrm{i}}$ retrotransposition events. a, $\mathrm{CHO}$ cells transfected with an EGFP plasmid in either the presence or absence of a dominantnegative TRF2 $(\triangle B \Delta M)$ expression plasmid were flow sorted and subjected to metaphase analysis. DAPI (4,6-diamidino-2-phenylindole)-stained metaphases from cells lacking (left panel) or containing (right panel) the TRF2 $(\Delta \mathrm{B} \Delta \mathrm{M})$ expression plasmid are shown. $\mathbf{b}$, A wild-type or endonuclease-deficient $\mathrm{L} 1$ was transfected into the indicated cell line in either the presence or absence of the TRF $2(\Delta \mathrm{B} \Delta \mathrm{M})$ plasmid and the resultant DNAs were subjected to the PCR/Southern blot assay. Size markers (bp) are shown. c, Sequences of the PCR products using the L1end186-telo3T primer pair. 
in the complemented cell lines demonstrated an increase in telomereassociated events; moreover, we detected telomere-associated retrotransposition from a wild-type L1 (Supplementary Fig. 3e-g and Supplementary Table 3b).

The inability to complement the $\mathrm{EN}_{\mathrm{i}}$ retrotransposition and anaphase bridge phenotypes in V3 cells requires further exploration. It is possible that $\mathrm{V} 3$ cells have accumulated lesions that are not present in the parental cell line, but contribute to the elevated efficiency of $\mathrm{EN}_{\mathrm{i}}$ retrotransposition. Alternatively, species-specific differences between the DNA-PKcs proteins used in these experiments may prevent complementation of the dysfunctional telomere phenotype $e^{20,24}$. In either case, these data argue that the NHEJ defect and dysfunctional telomere phenotypes are genetically separable.

We then tested whether destabilizing telomeres in XRCC4-deficient cells by expressing a dominant-negative allele of human TRF2 would allow a suitable substrate for $\mathrm{EN}_{\mathrm{i}}$ retrotransposition ${ }^{25}$. TRF2 is a telomere-binding protein required for the protection of chromosome ends ${ }^{15}$. Consistent with previous studies ${ }^{25,26}$, control experiments indicated that expression of the dominant-negative human TRF2 protein leads to chromosomal fusions in the NHEJ-proficient 4364a and AA8 parental cell lines (Fig. 3a). Next, we demonstrated that telomereassociated $\mathrm{EN}_{\mathrm{i}}$ retrotransposition events are readily observed in XRCC4-deficient cells expressing the dominant-negative human TRF2 protein, but not in control cell lines expressing the same protein (Fig. 3b, c). These data are consistent with the hypothesis that a defect in NHEJ allows L1 to use a dysfunctional telomere as an integration substrate ${ }^{26,27}$.

We conclude that $\mathrm{EN}_{\mathrm{i}}$ retrotransposition can occur in an orientation-specific manner at terminal telomere repeats. We propose that dysfunctional telomeres generated either by a loss of DNA-PKcs or the expression of a dominant-negative allele of human TRF2 in an NHEJ-deficient cell line allow the L1 retrotransposition machinery to use the 3' $\mathrm{OH}$ present at a dysfunctional telomere as a primer to initiate $\mathrm{EN}_{\mathrm{i}}$ retrotransposition (Fig. 4) ) $^{9-11,26,27}$. The finding that the L1 reverse transcriptase does not require terminal base pairing between the primer and template to initiate reverse transcription provides biochemical support for this model ${ }^{28}$.

We further speculate that integration of an L1 at the end of a chromosome would lead to chromosomal rearrangements, perhaps by initiating bridge-breakage-fusion cycles. Indeed the products of bridge-breakage-fusion cycles may provide recombination and/or

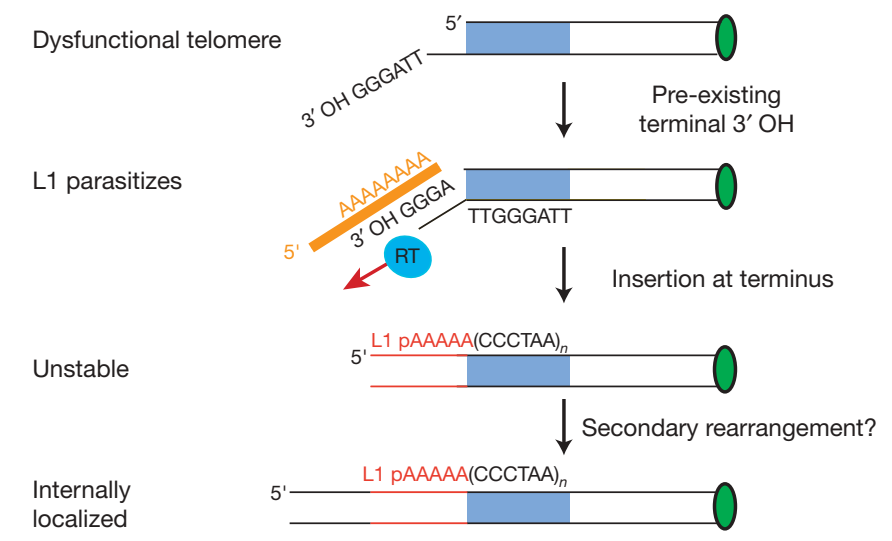

Figure 4 | Model for EN $_{\mathrm{i}}$ retrotransposition in NHEJ-deficient cells containing dysfunctional telomeres. A $3^{\prime} \mathrm{OH}$ at a dysfunctional telomere can serve as a primer for reverse transcription of L1 RNA during $E_{i}$ retrotransposition. The blue rectangle represents the telomere of a chromosome; the green oval depicts the centromere; the orange line indicates L1 RNA; the red line indicates the L1 cDNA; the blue circle symbolizes the L1 RT. It is unclear whether base pairing between the L1 mRNA poly(A) tail and the thymidine residues at the telomere stabilizes priming, and how the resultant retrotransposition event is resolved. However, the event may be unstable, leading to secondary rearrangements and internal localization of the L1. initiation substrates for $\mathrm{EN}_{\mathrm{i}}$ retrotransposition, leading to the structural features observed in insertions 5 and 9, respectively (Fig. 1b). Notably, we cannot formally exclude the possibility that breaks at interstitial telomeres can also act as substrates for $\mathrm{EN}_{\mathrm{i}}$ retrotransposition. However, the simplest explanation for our data is that dysfunctional telomeres can serve as substrates for $\mathrm{EN}_{\mathrm{i}}$ retrotransposition.

\section{METHODS}

Oligonucleotide sequences and constructs used in this study. The sequences and constructs used in this study are described in detail in Supplementary Information.

L1 retrotransposition assay. The 3' untranslated region of a retrotranspositioncompetent human L1 (L1.3) contains either a blasticidin or neomycin reporter (Rep) cassette designed to select retrotransposition events ${ }^{4,6,16}$. The relative positions of the CMV promoter (P) and SV40 late polyadenylation signal (pA) used for L1 expression are indicated in Fig. 1a. The relative positions of the SV40 promoter $\left(\mathrm{P}^{\prime}\right)$ and the thymidine kinase polyadenylation signal (inverted 'lollipop') required for reporter gene expression are also shown. Some of the mneoI-based constructs include a prokaryotic promoter and a bacterial origin of replication (ColE1, black rectangle) to allow the recovery of retrotransposition events as autonomously replicating plasmids in Escherichia coli ${ }^{16}$. The reporter gene is interrupted by an intron in the same transcriptional orientation as the L1. This arrangement ensures that the reporter transcript will only be translated after L1 retrotransposition. A modified version of a transient transfection protocol was used to introduce the L1s into cells ${ }^{6,29}$ (see Supplementary Information for details).

Recovery of retrotransposition events. Genomic DNA was isolated from G418resistant clonal $\mathrm{CHO}$ cell lines harbouring an L1 retrotransposition event, and the events were characterized as described previously ${ }^{16}$ (see Supplementary Information for details).

Analyses used. PCR and Southern blot analyses were performed using standard procedures (see Supplementary Information for details). FISH, anaphase bridge analyses, immunocytochemistry and metaphase analyses were performed using standard procedures (see Supplementary Information for details).

Characterization of mDNA-PKcs comp5 and comp15. The phenotypes of the mDNA-PKcs comp5 and mDNA-PKcs comp 15 cell lines were characterized with respect to protein levels, $\mathrm{V}(\mathrm{D}) \mathrm{J}$ recombination, radiation sensitivity and $\mathrm{EN}_{\mathrm{i}}$ retrotransposition (see Supplementary Information for details).

\section{Received 9 October 2006; accepted 2 January 2007.}

1. International Human Genome Sequencing Consortium. Initial sequencing and analysis of the human genome. Nature 409, 860-921 (2001).

2. Brouha, B. et al. Hot L1s account for the bulk of retrotransposition in the human population. Proc. Natl Acad. Sci. USA 100, 5280-5285 (2003).

3. Luan, D. D., Korman, M. H., Jakubczak, J. L. \& Eickbush, T. H. Reverse transcription of R2Bm RNA is primed by a nick at the chromosomal target site: a mechanism for non-LTR retrotransposition. Cell 72, 595-605 (1993).

4. Moran, J. V. et al. High frequency retrotransposition in cultured mammalian cells. Cell 87, 917-927 (1996).

5. Feng, Q., Moran, J. V., Kazazian, H. H. Jr \& Boeke, J. D. Human L1 retrotransposon encodes a conserved endonuclease required for retrotransposition. Cell 87, 905-916 (1996).

6. Morrish, T. A. et al. DNA repair mediated by endonuclease-independent LINE-1 retrotransposition. Nature Genet. 31, 159-165 (2002).

7. Pardue, M. L. \& DeBaryshe, P. G. Retrotransposons provide an evolutionarily robust non-telomerase mechanism to maintain telomeres. Annu. Rev. Genet. 37, 485-511 (2003).

8. Lingner, J. et al. Reverse transcriptase motifs in the catalytic subunit of telomerase. Science 276, 561-567 (1997).

9. Goytisolo, F. A., Samper, E., Edmonson, S., Taccioli, G. E. \& Blasco, M. A. The absence of the DNA-dependent protein kinase catalytic subunit in mice results in anaphase bridges and in increased telomeric fusions with normal telomere length and G-strand overhang. Mol. Cell. Biol. 21, 3642-3651 (2001).

10. Gilley, D. et al. DNA-PKcs is critical for telomere capping. Proc. Natl Acad. Sci. USA 98, 15084-15088 (2001).

11. Bailey, S. M. et al. DNA double-strand break repair proteins are required to cap the ends of mammalian chromosomes. Proc. Natl Acad. Sci. USA 96, 14899-14904 (1999)

12. Bailey, S. M., Cornforth, M. N., Kurimasa, A., Chen, D. J. \& Goodwin, E. H. Strandspecific postreplicative processing of mammalian telomeres. Science 293 , 2462-2465 (2001).

13. Takai, H., Smogorzewska, A. \& de Lange, T. DNA damage foci at dysfunctional telomeres. Curr. Biol. 13, 1549-1556 (2003).

14. Hao, L. Y., Strong, M. A. \& Greider, C. W. Phosphorylation of H2AX at short telomeres in T cells and fibroblasts. J. Biol. Chem. 279, 45148-45154 (2004). 
15. de Lange, T. Shelterin: the protein complex that shapes and safeguards human telomeres. Genes Dev. 19, 2100-2110 (2005).

16. Gilbert, N., Lutz-Prigge, S. \& Moran, J. V. Genomic deletions created upon LINE-1 retrotransposition. Cell 110, 315-325 (2002)

17. Gilbert, N., Lutz, S., Morrish, T. A. \& Moran, J. V. Multiple fates of I1 retrotransposition intermediates in cultured human cells. Mol. Cell. Biol. 25, 7780-7795 (2005)

18. Faravelli, M. et al. Molecular organization of internal telomeric sequences in Chinese hamster chromosomes. Gene 283, 11-16 (2002).

19. Taccioli, G. E. et al. Targeted disruption of the catalytic subunit of the DNA-PK gene in mice confers severe combined immunodeficiency and radiosensitivity. Immunity 9, 355-366 (1998).

20. Blunt, T. et al. Identification of a nonsense mutation in the carboxyl-terminal region of DNA-dependent protein kinase catalytic subunit in the scid mouse. Proc. Natl Acad. Sci. USA 93, 10285-10290 (1996).

21. Whitmore, G. F., Varghese, A. J. \& Gulyas, S. Cell cycle responses of two X-ray sensitive mutants defective in DNA repair. Int. J. Radiat. Biol. 56, 657-665 (1989).

22. Blunt, T. et al. Defective DNA-dependent protein kinase activity is linked to V(D)J recombination and DNA repair defects associated with the murine scid mutation. Cell 80, 813-823 (1995).

23. Meek, K., Gupta, S., Ramsden, D. A. \& Lees-Miller, S. P. The DNA-dependent protein kinase: the director at the end. Immunol. Rev. 200, 132-141 (2004).

24. Beamish, H. J. et al. The C-terminal conserved domain of DNA-PKcs, missing in the SCID mouse, is required for kinase activity. Nucleic Acids Res. 28, 1506-1513 (2000)

25. van Steensel, B., Smogorzewska, A. \& de Lange, T. TRF2 protects human telomeres from end-to-end fusions. Cell 92, 401-413 (1998).

26. Smogorzewska, A., Karlseder, J., Holtgreve-Grez, H., Jauch, A. \& de Lange, T. DNA ligase IV-dependent NHEJ of deprotected mammalian telomeres in G1 and G2. Curr. Biol. 12, 1635-1644 (2002).

27. Celli, G. B. \& de Lange, T. DNA processing is not required for ATM-mediated telomere damage response after TRF2 deletion. Nature Cell Biol. 7, 712-718 (2005).

28. Kulpa, D. A. \& Moran, J. V. Cis-preferential LINE-1 reverse transcriptase activity in ribonucleoprotein particles. Nature Struct. Mol. Biol. 13, 655-660 (2006).

29. Wei, W., Morrish, T. A., Alisch, R. S. \& Moran, J. V. A transient assay reveals that cultured human cells can accommodate multiple LINE-1 retrotransposition events. Anal. Biochem. 284, 435-438 (2000)
30. Dombroski, B. A., Mathias, S. L., Nanthakumar, E., Scott, A. F. \& Kazazian, H. H. Jr. Isolation of an active human transposable element. Science 254, 1805-1808 (1991).

Supplementary Information is linked to the online version of the paper at www.nature.com/nature.

Acknowledgements We thank A. M. DesLauriers for help with flow cytometry and cell sorting; R. Lyons for help with sequencing; T. de Lange for discussions and the dominant-negative TRF2 expression construct; $M$. Abe for the murine DNA-PKcs expression construct; G. Hammer and T. Else for help with the metaphase analysis; and C. Greider for discussions and use of equipment and reagents for immunocytochemistry experiments. We thank T. Else, T. Glover, T. Glaser,

N. Howlett, T. Wilson and current members of the Moran laboratory for discussions during the course of this work. T.A.M. was supported in part by a NIH training grant and is now a Leukemia and Lymphoma Society Fellow. J.L.G.-P. was supported in part by a MEC/Fulbright postdoctoral grant. G.E.T. is partially supported by a grant from the Human Frontier Science Program. T.D.S was supported in part by a grant from the National Institutes of Health. J.S. was supported in part by a grant from the Pew Foundation. J.V.M was supported in part by grants from the W.M. Keck Foundation and the National Institutes of Health.

Author Contributions T.A.M is co-first author and is a corresponding author. She contributed to the original concept, designed and performed experiments, analysed the data, and wrote the first draft of the manuscript. J.L.G.-P. is co-first author. He contributed to the concept, designed and performed experiments, analysed the data, and helped write and revise the manuscript. T.D.S and G.E.T. contributed reagents, helped with data interpretation and provided helpful comments during the course of this study. J.S. contributed the murine DNA-PKcs complemented cell lines, performed functional analyses on those cell lines, helped with data analysis, and helped revise the manuscript. J.V.M. is the senior author. He contributed to the original concept, analysed the data, revised the manuscript and provided financial support.

Author Information Reprints and permissions information is available at www.nature.com/reprints. The authors declare no competing financial interests. Correspondence and requests for materials should be addressed to J.V.M (moranj@umich.edu) or T.A.M. (morrisht@jhmi.edu). 